\title{
Analysis of maternal mortality: a retrospective study at tertiary care centre
}

\author{
Surekha N. Khandale*, Kshama Kedar
}

Department of Obstetrics and Gynecology, Indira Gandhi Government Medical College, Nagpur, Maharashtra, India

Received: 22 January 2017

Revised: 31 January 2017

Accepted: 28 February 2017

*Correspondence:

Dr. Surekha N. Khandale,

E-mail: drsurekha.narayankhandale@gmail.com

Copyright: () the author(s), publisher and licensee Medip Academy. This is an open-access article distributed under the terms of the Creative Commons Attribution Non-Commercial License, which permits unrestricted non-commercial use, distribution, and reproduction in any medium, provided the original work is properly cited.

\section{ABSTRACT}

Background: Mother is the pillar of the family and maternal deaths during pregnancy and delivery are great loss to baby, family, society and country too. Epidemiological data pertaining to maternal mortality is valuable in each set-up to design interventional programs to reduce the ratio favourably. This study was design to evaluate the mortality rate in our hospital, to assess the epidemiological aspects and causes of maternal mortality, types of delay, and to suggest recommendations for improvement. Aim of the study was to analyse the causes of maternal death at tertiary care centre. Objective of the study was to analyse causes of maternal death and type of delay, and to suggest measures to reduce it.

Methods: A retrospective study done at a tertiary level care centre from January 2011 to June15. Demographic data and other data were collected from maternal death review forms and case records. Data studied and analysed.

Results: Most maternal deaths were due to obstetric causes like eclampsia (16.66\%), preeclampsia (11.53\%), anaemia $(14.10 \%)$ and haemorrhage $(10.25 \%)$. Associated co-morbid medical conditions hepatitis $(6.41 \%)$ and heart disease $(5.12 \%)$ were in the top list. Majority women were from rural area $(69.23 \%)$, belonged to below poverty line $(76.92 \%)$, had less than three visits $(64.09 \%)$, received care at periphery below the level of specialist sub-district hospital. $94.87 \%$ were referred, and travelled more than 4 hours to reach hospital $(88.44 \%)$. In majority cases Type 1 delay was most common $(85.89 \%)$ comparatively to Type 2 and 3 delay.

Conclusions: High risk cases should be identified. Early referral, easy transport, continued skill based training, monitoring of health services can reduce maternal mortality. Special training should be conducted for ASHA workers and ANM who generally works at grass root level in our country. Continued medical training is required for medical officers who are working at PHC and sub district hospital for early recognition of high risk women and their referral in time to higher centers to avoid maternal near miss or death.

Keywords: Accredited social health activist, Antenatal midwife. Maternal mortality

\section{INTRODUCTION}

Worldwide 5,36000 women are dying of pregnancy related complication annually. India is carrying $25 \%$ of global burden. One of the Millenium development goal is to reduce maternal mortality to 109 till 2015. Government of India is trying to reduce maternal mortality through various programmes like Jananisuraksha Yojana, Jananishishu Suraksha Yojana and Rajiv Gandhi Jeevandayi Yojana. Maternal death audits are being conducted at institutional level, district level. Various delays in care are being identified, Medical officers are being trained so they can provide skilled and effective care. Ambulance care is free of cost for mothers and neonates.

According to the World Health Organization (WHO), A Maternal death is defined as death of any woman while 
being pregnant or within forty-two completed days of termination of pregnancy irrespective of duration or site of pregnancy from any cause related to or aggravated by pregnancy but not from accidental or incidental causes. ${ }^{1}$ Maternal mortality rate is defined as maternal death per 1,00,000 live births. ${ }^{1}$ Pregnancy and childbirth are joyful events but sometimes may land up with complications and death if risk factors are not identified and corrected at proper time. Death of a woman and mother is tragic loss to child, community and nation as a whole. Every minute there is one maternal death all over the world. At every five minute, there is one maternal death in India. Almost half a million women die every year from complications during pregnancy and childbirth. About $99 \%$ of these women are from developing world with over $90 \%$ concentrated in Africa and Asia.

In 1938, maternal mortality in India was 2000 which was declined to 1000 in 1959 and then it declined to 540 in $1999 .^{2}$ Current maternal mortality ratio is 167 per $1,00,000$ live births which is far higher than millennium development goal 2020 i.e. 109 per 1,00,000, live births. The tragedy is that these deaths are largely preventable. The progress in maternal health has been uneven, inequitable, and unsatisfactory. The risk of a woman dying as a result of a pregnancy and childbirth during her lifetime is about 1 in 6 in Afghanistan compared with 1 in 30,000 in Northern Europe. ${ }^{2}$ United Nation (UN) report card on Millennium Development Goal-5 concluded that little progress had been made in sub-Saharan Africa where half of all maternal deaths take place. The progress shown by the South Asian countries including India which accounts for $25 \%$ of all maternal deaths is also not impressive. ${ }^{3}$ Also maternal mortality is just a tip of iceberg, behind each mortality there are at least 20 mothers who experiences severe morbidity. Direct obstetric causes like haemorrhage, hypertensive disorders of pregnancy, septic abortion and medical cause like hepatitis, heart disease in pregnancy are common causes of maternal death. Anaemia is the most important indirect cause of maternal mortality. As these causes are preventable by early detection of high risk factors and early intervention during pregnancy, and can help to reduce the maternal mortality.

This study was carried out at Indira Gandhi government medical college, Nagpur a tertiary care centre in central India where large numbers of patients are referred from rural parts of Maharashtra and neighbouring states. This study was done to analyse causes of maternal deaths, factors responsible for death, levels of delay so early intervention can be done to reduce all these factors at proper time. Objectives of present study are:

- To assess the epidemiological aspects of maternal mortality

- To assess the causes of maternal mortality

- To suggest the ways to reduce the MMR.

\section{METHODS}

This was a retrospective study carried out at Indira Gandhi Government Medical College Nagpur, Maharashtra, which is a tertiary care health centre of central India catering many district, Sub-district and PHC's and adjoining states for health services. Demographic and other data was collected from individual case records and maternal death review forms from Jan 2011 to Jun 2015 were included. As per definition of maternal death, death due to suicide and homicide were excluded from the study. Total 78 maternal deaths were carefully studied and analyzed.

\section{Types of delay according to Maternal Death review form}

- Type 1 delay - delay in decision making to seek help.

- Type 2 delay - delay in transport due to poor roads and unavailability of vehicles,

- Type 3 delay - delay at institutional level.

Detailed history regarding demographic characters, previous antenatal care along with type of delay noted. Causes of death, Level of ANC care, and referral hospital and referral time noted along with duration of care received at this hospital and time of death.

\section{RESULTS}

The epidemiological characteristics of maternal deaths are shown in Table 1. It is observed that 38 (48.71\%) deaths were from 25- 30 year of age followed by 23 (29.48\%) deaths were from 19-25 year of age. In 30-35 year, there were 14 deaths $(17.94 \%)$. More maternal death $54(69.23 \%)$ were from rural areas as compared to urban areas $(69.23 \%)$.

Maximum maternal deaths were reported in patients with less than 3 visits $(64.09 \%)$ as compared to patients with more than 3 visits (35.89\%). Most maternal deaths $(76.09 \%)$ were reported in low socioeconomic status. Majority deaths were of women who were attending hospitals below the level of speciality care $(56.39 \%)$. Majority deaths were from women who took more than four hours to reach hospital after referral $(88.44 \%)$. Majority patients died in postpartum status $(53.84 \%)$. In majority $(85.89 \%)$ patients it was Type 1 delay. In the study period, $61.51 \%$ of maternal deaths were due to direct causes. Eclampsia and preeclampsia (28.19\%), anaemia $(14.10 \%)$, Haemorrhage $(10.25 \%)$ were main direct causes of obstetric death.

In the study period, $39.1 \%$ of the maternal deaths were due to indirect causes. ARDS, hepatitis, heart disease accounted for $7.69 \%, 6.41 \%$ and $5.12 \%$ of maternal deaths respectively. Considering type of delay type 1 delay $(85.99 \%)$ was commonest followed by Type 2 $(10.25 \%)$, type 3 delay was least common $(3.84 \%)$. 
Table 1: Sociodemographic characteristics.

\begin{tabular}{|c|c|c|}
\hline Sociodemographic character & Cases & Percentage \\
\hline \multicolumn{3}{|l|}{ No. of ANC visits } \\
\hline Nil & 7 & 8.97 \\
\hline$<3$ visits & 43 & 55.12 \\
\hline$>3$ visits & 28 & 35.89 \\
\hline \multicolumn{3}{|l|}{ Places from where patient was } \\
\hline \multicolumn{3}{|l|}{ referred } \\
\hline Primary health centre & 9 & 11.53 \\
\hline Rural hospital & 17 & 21.79 \\
\hline Subdistrict hospital & 20 & 25.64 \\
\hline Distict hospital & 24 & 30.76 \\
\hline Private hospital & 4 & 5.12 \\
\hline \multicolumn{3}{|l|}{ Type of care provider } \\
\hline ANM & 14 & 17.94 \\
\hline $\mathrm{MO}, \mathrm{PHC}$ & 14 & 17.94 \\
\hline $\mathrm{MO}, \mathrm{RH}$ & 16 & 20.51 \\
\hline Specialist subdistrict hospital & 10 & 12.82 \\
\hline Specialist district hospital & 16 & 20.51 \\
\hline Tertiary care Hospital & 4 & 5.12 \\
\hline Private & 4 & 5.12 \\
\hline \multicolumn{3}{|c|}{ Duration to reach referral hospital } \\
\hline$<4$ hour & 9 & 11.53 \\
\hline 4-8 hour & 22 & 28.20 \\
\hline $8-12$ hour & 38 & 48.71 \\
\hline$>12$ hour & 9 & 11.53 \\
\hline \multicolumn{3}{|l|}{ Status at the time of death } \\
\hline Abortion & 11 & 14.10 \\
\hline Anteparum & 19 & 24.35 \\
\hline Intrapartum & 6 & 7.69 \\
\hline Postpartum & 42 & 53.84 \\
\hline \multicolumn{3}{|l|}{ Type of delay* } \\
\hline Type 1 & 67 & 85.89 \\
\hline Type 2 & 8 & 10.25 \\
\hline Type 3 & 3 & 3.84 \\
\hline
\end{tabular}

Table 2: Co-morbid medical conditions causing death.

\begin{tabular}{|lll|}
\hline Medical condition & Cases & Percentage \\
\hline Hepatitis & 5 & 6.41 \\
\hline Heart Disease & 4 & 5.12 \\
\hline Dengue & 1 & 1.28 \\
\hline Malaria & 2 & 2.56 \\
\hline CVE & 3 & 3.84 \\
\hline Tuberculosis & 2 & 2.56 \\
\hline ARDS & 6 & 7.69 \\
\hline Diabetes & 2 & 2.56 \\
\hline Sickle cell disease & 2 & 2.56 \\
\hline Viral encephalitis & 1 & 1.96 \\
\hline Influenza H1 N1 & 2 & 2.56 \\
\hline (n=30) & &
\end{tabular}

Maximum patients in our study died after 48 hours (83.33\%). $16.65 \%$ patients died within 48 hours. Considering complications in patient's intensive care unit admission was most common $(97.43 \%)$, followed by extended intubation more than 12 hours $(87.17 \%)$, organ system failure $(57.69 \%)$, Blood transfusion more than 3 $(53.84 \%)$ a least common was operative intervention $(10.25 \%)$.

Table 3: Obstetric causes of death.

\begin{tabular}{|lll|}
\hline Causes & Cases & Percentage \\
\hline Eclampsia & 13 & 16.66 \\
\hline Severe preeclampsia & 09 & 11.53 \\
\hline Anemia & 11 & 14.10 \\
\hline Septic abortion & 06 & 7.69 \\
\hline Hemorrhage & 08 & 10.25 \\
\hline Amniotic fluid embolism & 01 & 1.28 \\
\hline
\end{tabular}
$(\mathrm{n}=48)$

Table 4: Admission death interval time.

\begin{tabular}{|lll|}
\hline Time (hours) & Cases & Percentage \\
\hline$<4$ & 0 & 0 \\
\hline $4-24$ & 4 & 5.12 \\
\hline $24-48$ & 9 & 11.53 \\
\hline$>48$ & 65 & 83.33 \\
\hline
\end{tabular}

Table 5: Complications in patients.

\begin{tabular}{|lll|}
\hline Type of complication & Cases & Percentage \\
\hline Organ system failure & 45 & 57.69 \\
\hline ICU admission & 76 & 97.43 \\
\hline Blood transfusion $>3$ & 42 & 53.84 \\
\hline Extended intuation $>12$ hrs & 68 & 87.17 \\
\hline Operative intervention & 8 & 10.25 \\
\hline
\end{tabular}

\section{DISCUSSION}

Maternal mortality is an index of reproductive health of the society. High incidence of maternal deaths reflects poor quality of maternal services, late referral and low socioeconomic status of the community. Various studies in India in the last 15 years have shown wide variation in MMR ranging from 47/100000 to 625/ 100000 births. ${ }^{4-9}$ Madhu Jain has reported a very high MMR of 2270/100000. ${ }^{5}$ This study has comparatively high MMR, which could be due to the fact, that our hospital isatertiary care center and receives a lot of complicated referrals from Madhya Pradesh and rural areas at a very late stage.

In our study, $78.19 \%$ of maternal deaths were in the age group of 18-30 years, as highest numbers of births are reported in this age group. More maternal deaths were reported in women from rural areas $(69.23 \%)$, had less than 3 ANC visits $(64.09 \%)$, and women belonging to low socioeconomic status. (76.09\%). All our findings were similar to studies by Jain, Jadhav, Pal, Onakewhor, and Shah. ${ }^{5-9}$ In our study $61.51 \%$ of maternal deaths were due to direct causes. Eclampsia and preeclampsia (28.19\%), anaemia (14.10\%), Haemorrhage (10.25\%) were main direct causes of obstetric death. Our findings were consistent with studies by Jain, Jadhav, Pal, Onakewhor, and Shah, Murthy. ${ }^{5-10}$ In our study $39.1 \%$ of 
the maternal deaths were due to indirect causes. ARDS, hepatitis, heart disease accounted for $7.69 \%, 6.41 \%$ and $5.12 \%$ of maternal deaths respectively. Maximum patients in our study died after 48 hours (83.33\%). $16.65 \%$ patients died within 48 hours. Considering complications in patient's intensive care unit admission was most common $(97.43 \%)$, followed by extended intubation more than 12 hours $(87.17 \%)$, organ system failure $(57.69 \%)$, Blood transfusion more than 3 $(53.84 \%)$ a least common was operative intervention $(10.25 \%)$.

Even today large number of maternal deaths is due to the classical triad of haemorrhage, sepsis, and eclampsia. All these are preventable causes of maternal mortality provided the treatment started in time. Unfortunately, in many cases, patients were referred from nearby states very late, in critical condition, unaccompanied by health worker. Most of these deaths are preventable if patients are given appropriate treatment at periphery and timely referred to higher centers. Health education of pregnant mothers and community about warning signs, training of ASHA workers, Training of medical officers and staff nurses working in rural areas by programs like basic emergency obstetric care (BEMOC) and skilled attendant at birth $(\mathrm{SAB})$ training gives a ray of hope of reducing maternal mortality. As Type 1 delay was commonest maternal deaths can be prevented by improving health education, by improving health care facilities in rural areas by ensuring round the clock availability of certain drugs like injection magnesium sulphate, tablet misoprostol as most maternal deaths in rural areas are still due to eclampsia and postpartum haemorrhage.

Early detection of high risk cases and timely referral of these patients at tertiary care centre, promoting $100 \%$ institutional delivery, improving transportation, skilled manpower at every level can help in reducing maternal mortality. Proper implementation of National rural health mission (NRHM) can play an important role in reducing maternal mortality.

\section{CONCLUSION}

In today's modern era of medicine most maternal deaths are seen in women from rural areas, less educated, unbooked and patients from low socioeconomic status, who had to travel a lot to reach a tertiary care centre. Also, there is no awareness of warning signs in pregnancy. High risk cases should be identified. Early referral, easy transport, continued skill based training, up-gradation of hospitals, monitoring of health services can reduce maternal mortality.

Funding: No funding sources Conflict of interest: None declared

Ethical approval: The study was approved by the Institutional Ethics Committee

\section{REFERENCES}

1. Park K. Preventive medicine in obstetric, Paediatrics andgeriatrics: Park's Text Book of Preventive and Social Medicine. 20 $0^{\text {th }}$ edition. Jabalpur: M/S Banarasi Das Bhanot. 2009;479-83.

2. Govt. of India (1962) Report of the Health survey and Planning Committee, Vol 1. Govt. of India, Ministry of health and Family Welfare (1984) Annual report 1983-84.

3. United nations mileenium development goals report. 2015.

4. Puri A, Yadav, Jain N. Maternal mortality in an urban care hospital of north Insia. J Obstet Gynaecol India. 2011;61:280-5.

5. Jain M, Maharaje S, Maternal mortality: A retrospective analysis of ten years in atertiary care hospital. Indian J Prev Soc Med. 2003;34:103-11.

6. Jadhav AJ, Rote PG. Maternal mortality-changing trends. J Obstet Gynaecol India. 2007;57:398-400.

7. Pal A, Ray P, Hazra S, Mondal TK. Review of changing trends in maternal mortality in a rural medical college in west Bangal. J Obstet Gynecol India. 2005;55:521-4.

8. Onakewhor JU, Gharoro EP. Changing trends in maternal mortality in a developing country. Niger $\mathbf{J}$ Clin Pract. 2008;11:111-20.

9. Shah RJ, AliI, Banday A, Faziili A, Khan I. Analysis of maternal mortality in a small teaching hospital attached to tertiary care hospital. Indian $\mathbf{J}$ Community Med. 2008;33:260-2.

10. Murthy BK, Murthy MB. Maternal mortality in tertiary care hospital: A 10 yr review International Journal of Preventive Medicine. 2013;4(1):105-9.

Cite this article as: Khandale SN, Kedar K. Analysis of maternal mortality: a retrospective study at tertiary care centre. Int J Reprod Contracept Obstet Gynecol 2017;6:1610-3. 